\title{
El itinerario cultural del ferrocarril de Antioquia como escenario de creaciones y representaciones: una apuesta a su activación
}

\author{
Germán Jaramillo
}

Introducción

La empresa regional ferroviaria de Antioquia se incluye entre los muchos proyectos expansionistas de Colombia y América Latina que tuvieron asiento luego de la guerras de independencia en el siglo XIX, y que movido por una visión de apertura comercial de intercambio de bienes de consumo y de servicio, abrió las puertas a los efectos de una influyente revolución tecnológica e industrial que ya estaba cosechando sus frutos en Europa y Norteamérica. Producto de estas dinámicas de intercambio, se fue gestando en Antioquia un cambio de paradigma de la otrora provincia pobre y marginal, por el de una región rica, abierta y competitiva en los mercados internacionales, que fue reflejo de un nuevo imaginario cultural e ideario republicano y que tuvo su marca de identidad en lo que finalmente se constituyó como la "cultura industrial y ferroviaria de Antioquia".

El núcleo significativo del problema en esta investigación se concentra en la necesidad de descifrar, como consecuencia del aparente nivel de abandono, desarticulación y obsolescencia de las estructuras, paisajes y dinámicas culturales de intercambio asociadas al ferrocarril de Antioquia, alternativas de gestión y activación, a partir del reconocimiento, no solo de sus valores patrimoniales: históricos, tecnológicos, contextuales y significativos, sino de una puesta local de diálogo de saberes en su condición especial de "itinerario cultural", escenario de apropiaciones y valores de conjunto compartidos en su íntima relación con el territorio, las comunidades y la cultura.

De lo anteriormente expuesto se deriva el reto de comprender cuál es el lugar común (valores de conjunto compartidos) y qué vínculos (redes de intercambio y cooperación) podemos establecer en una estrategia de gestión de la ruta, que permita su adaptación a las nuevas dinámicas y desafíos de las comunidades, en la consolidación y fortalecimiento de los imaginarios, sentimientos de apropiación y significación (memoria-identidad), de cara a su activación como sistema de movilidad regional (estructurante del territorio) e itinerario cultural.

Con base en lo teórico se plantea la revisión de las nociones y categorías conceptuales que han resultado de los ejes problemáticos, a partir de los fundamentos epistemológicos del objeto patrimonial como sistema territorial, en la perspectiva de un conjunto integrado de sistemas de objetos y accio-

* Cómo citar este artículo: Jaramillo, G. (2017). El itinerario cultural del ferrocarril de Antioquia como escenario de creaciones y representaciones: una apuesta a su activación. Apuntes, 30(1), 144-155. https://doi.org/10.11144/Javeriana.apc30-1.icfa 


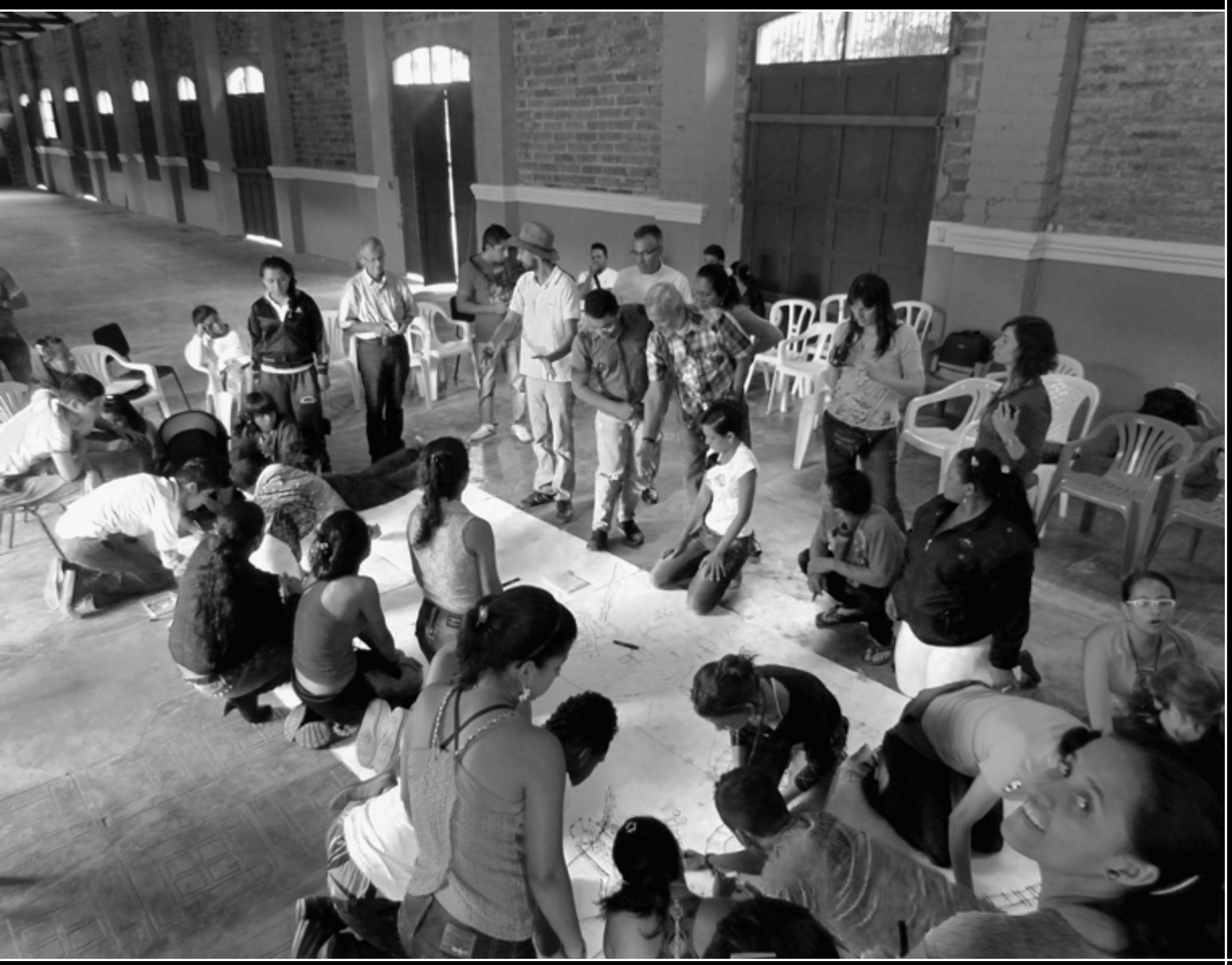

Taller participativo: "Creemos y re-creemos nuestra memoria", con las comunidades de Cisneros y Santo Domingo, en la antigua estación Cisneros

Fotografía:

Germán Jaramillo 


\title{
El itinerario cultural del ferrocarril de Antioquia como escenario de creaciones y representaciones: una apuesta a su activación
}

\author{
The Cultural ltinerary of the Antioquia Railway as the Scenario for \\ Creations and Representations: A Bet on its Activation \\ 0 itinerário cultural do railway de Antioquia como cenário de \\ criações e representações: uma aposta na sua ativação
}

\begin{abstract}
Germán Jaramillo
german.jaramillo@usbmed.edu.co

Arquitecto restaurador con estudios de doctorado en Artes de la Universidad de Granada, España (2015), tesis: Acercamiento a un modelo de gestión patrimonial del ferrocarril de Antioquia y su activación como itinerario cultural: Trayecto Botero-Cisneros. Estudios de maestría en Conservación del Patrimonio de la Universidad Internacional de Andalucía, Huelva, España (2006) y Restauración Arquitectónica de la Universidad Politécnica de Madrid, España, (1998). Docente investigador de la Facultad de Artes Integradas de la Universidad de San Buenaventura, Medellín desde el año 2000; director de la línea de investigación Memoria, Identidad y Cultura y líder del semillero de investigación en Patrimonio Industrial y Ferroviario. Experiencia en estudios y proyectos de inventario, valoración, catalogación, diagnóstico, intervención y gestión del patrimonio cultural inmueble del departamento de Antioquia desde 1987.

Resumen

La idea del ferrocarril de Antioquia como sistema estructurante del territorio y en particular como categoría patrimonial de itinerario cultural, nos plantea una lectura que va más allá de un simple listado de bienes muebles e inmuebles de interés cultural dispersos en una geografía y que en las últimas décadas han estado sometidos a su abandono y obsolescencia, con cambios significativos en las dinámicas de asentamiento, intercambio multidimensional y permanencia de sus comunidades aledañas. Un nuevo escenario de creaciones y representaciones que se construye desde la memoria y los imaginarios sociales ha permitido revelar claves de identidad que, en la categoría de itinerario cultural, se constituyen, como lo plantea el Icomos (2008), en valores de conjunto compartidos, y por tanto, en potencial emergente de gestión para su puesta en valor como recurso patrimonial desde la perspectiva del desarrollo a escala humana. Este trabajo permite develar aquellas versiones de identidad que se han construido en los ámbitos local y cotidiano de las comunidades ferroviarias y que trascienden el discurso oficial, con lo que el espectro de valoración se amplía al escenario intangible de las apropiaciones y significaciones, en la construcción de nuevos relatos, y por ende, de nuevos caminos hacia la activación y gestión participativa del itinerario ferroviario.
\end{abstract}

Palabras clave: itinerario cultural; patrimonio ferroviario; paisaje cultural; Imaginarios; memoria e identidad; apropiaciones y significaciones; gestión del patrimonio; ferrocarril de Antioquia

Abstract

The idea of the railroad of Antioquia as the structuring system of the territory, and particularly, as a patrimonial category of 'cultural itinerary,' raises a reading that goes beyond a simple list of movable and immovable property of cultural interest scattered in a geography -that in the last decades have been subject to abandonment and obsolescence- with significant changes in the dynamics of settlement, multidimensional exchange, and permanence of the surrounding communities. A new scenario of creations and representations, built from memory and social imaginaries, has allowed revealing identity keys that in the category of cultural itinerary are constituted as established by Icomos (2008), in shared common values. This, therefore, leads to emerging management potential to set its value as a heritage resource from the perspective of human scale development. This work allows revealing those identity versions that have been constructed from the local and daily environment of the railway communities and that transcend the official discourse, extending the spectrum of valuation over to the intangible scenario of appropriations and meanings, in the construction of new stories, and therefore, of new roads towards the activation and participative management of the railway itinerary.

Keywords: cultural itinerary; railway heritage; cultural landscape; Imaginary; memory and identity; appropriations and meanings; heritage management; Antioquia railway

Artículo de investigación

Recepción: 16 de junio de 2016

Aceptación: 15 de noviembre de 2017

Disponible en línea: 10 de diciembre de 2017
Resumo

A ideia do transporte ferroviário de Antioquia como sistema estruturante do território e em particular como categoria patrimonial de 'itinerário cultural', sugere uma leitura que vai mais para além de uma simples lista de bens móveis e imóveis de interesse cultural espalhados por uma geografia que nas últimas décadas tem estado submetidos ao seu abandono e obsolescência, com mudanças significativas nas dinâmicas de assentamento, troca multidimensional e permanência de suas comunidades vizinhas. Um novo cenário de criações e representações construídas desde a memória e os imaginários sociais permitiu revelar chaves de identidade, que, na categoria de itinerário cultural, constituem, como levanta Icomos (2008), valores de conjunto compartilhados, e por tanto, potencial emergente de gestão para sua valoração como recurso patrimonial, desde a perspectiva do desenvolvimento a escala humana. Este trabalho permite desvelar aquelas versões de identidade que se construíram desde o âmbito local e cotidiano das comunidades ferroviárias e transcendem o discurso oficial, ampliando o espectro de valoração ao cenário intangível das apropriações e significações, na construção de novos relatos, e por isso, de novos caminhos para a ativação e gestão participativa do itinerário ferroviário.

Palavras-chave: itinerário cultural; herança ferroviária; paisagem cultural; Imaginário; memória e identidade; apropriações e significados; gestão patrimonial; Antioquia railway

doi:10.11144/Javeriana.apc30-1.icfa 
nes (Santos, 2000); el cambio cualitativo en la interpretación de la noción patrimonial por una versión más abarcante e incluyente; y la cuestión del catálogo y la necesidad de generar nuevos campos de fichaje que trascienden el discurso autorizado del patrimonio al invocar la versión existencial de los actores.

\section{La categoría de itinerario cultural}

El conocimiento y puesta en valor del ferrocarril de Antioquia en su doble vertiente de sistema territorial e itinerario cultural, debe ser abordado en igual proporción, desde su doble consideración: de territorio, como espacio humanizado en constante transformación y resignificación, y de itinerario, como categoría multidimensional del patrimonio cultural; en otras palabras, un concepto de paisaje dinámico e integrador, inmutable, contenedor de múltiples identidades, y a la vez, de valores compartidos.

La metodología planteada en la Carta de Itinerarios Culturales (1comos, 2008) establece que para la investigación, valoración, protección, conservación, uso y gestión de los itinerarios culturales debe tener en cuenta "la envergadura y valor de conjunto, así como sus dimensiones territoriales", lo que implica que en esta propuesta se debe trascender del territorio como entorno geográfico, al territorio como patrimonio mismo, es decir, como patrimonio territorial, en la medida en que se convierte en una unidad indivisible e interdependiente de los demás elementos definitorios del itinerario.

Un nuevo concepto de territorio que trasciende su consideración occidental física y euclidiana, que si bien se ha complementado con versiones naturalistas y ambientalistas, ha descuidado su verdadera dimensión social como proceso antrópico de adaptación, asentamiento y transformación. La implantación en el territorio del ferrocarril de Antioquia como ruta surge de decisiones geopolíticas fundadas en intereses económicos de comercialización e intercambio comercial, que además buscaba aprovechar los ríos navegables del Cauca y Magdalena al interior del territorio, como enlaces del comercio con Europa y Norteamérica. Pero esto no es suficiente para reconocer su impacto en el territorio, pues en su proceso histórico se generaron a su paso rutas y focos de asentamiento, que permiten revisar los niveles de compromiso del sistema con el entorno social y territorial, y reconocer la construcción de nuevas territorialidades en el uso y transformación del espacio humanizado. Un ejercicio que supera el enunciado geométrico y ambientalista por un territorio o espacio "[...] no dado, sino construido" (Ortega, 1998). Además de trascender la percepción cultural estética del patrimonio como obra de arte excepcional a la concepción multidimensional de carácter ético, científico, social y pedagógico.

Si se parte de la premisa que el itinerario cultural no solo atraviesa un territorio o te-

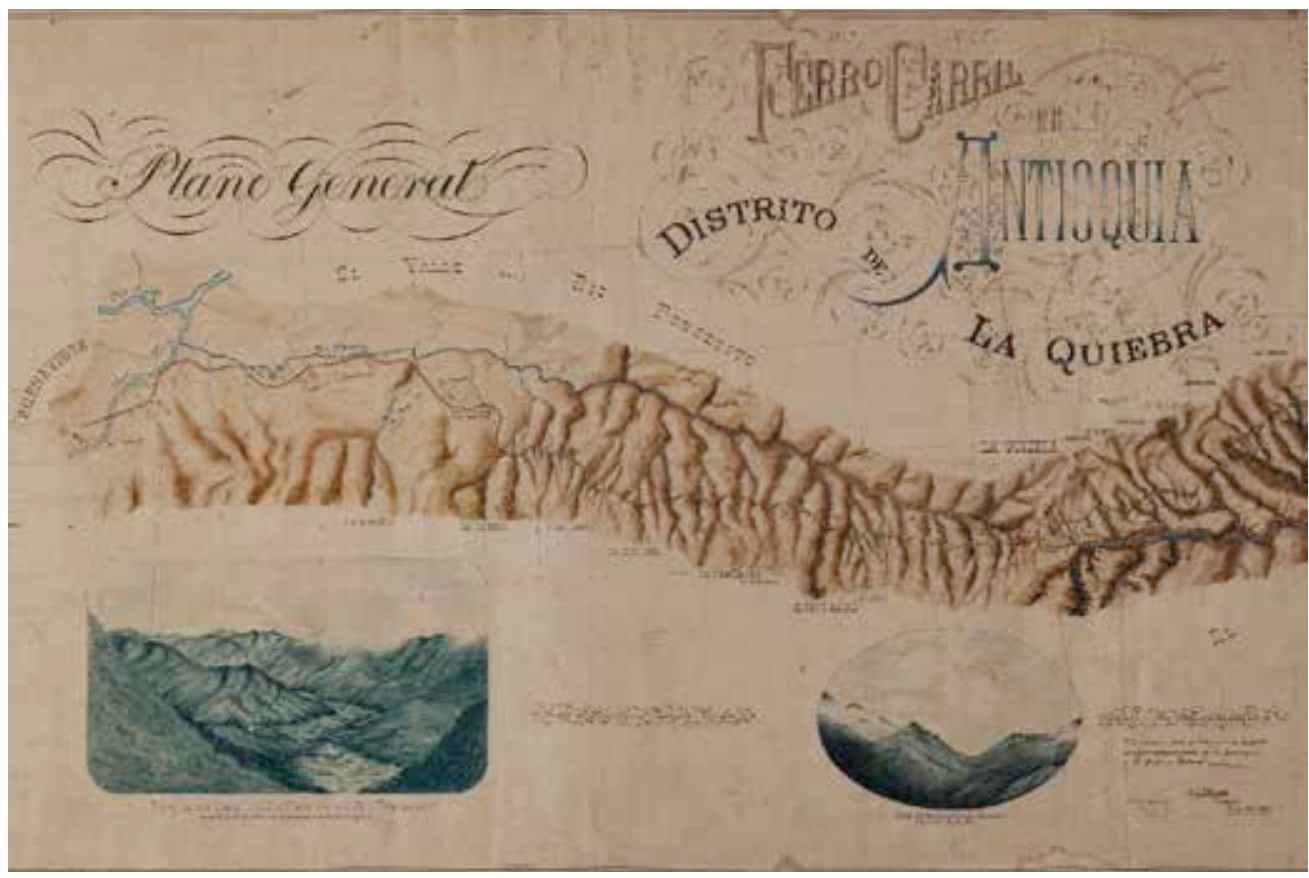

Figura 1:

Detalle del "Plano General. Ferro Carril de Antioquia. Distrito de La Quiebra. 1893", por G. T. Spender Fuente: Lenis, Jaramillo y Vélez (2010, p. 62). Original: Fundación Ferrocarril de Antioquia 
1 El debate entre la historia oficial que se cruza con relatos de sus actores en un proceso constante de retroalimentación entre los mitos y las realidades, narraciones y vivencias.

2 "Para evitar crear una confusión entre el estudio del patrimonio intangible de los itinerarios culturales (los cuales son el objeto específico de dedicación del CIIC) y la consideración aislada del patrimonio inmaterial fuera de ese contexto, se recuerda que el CIIC de ICOMOS debe abordar la consideración y tratamiento de los elementos intangibles como un valor incorporado a otros elementos o vestigios materiales (básicamente de carácter inmueble, por constituir éstos el ámbito encomendado a ICOMOS por su Estatutos), todos los cuales revelan la existencia de un itinerario y le prestan un sentido conjunto. Es decir, los valores intangibles son de interés para el CIIC en tanto en cuanto se hallen relacionados con la pervivencia palpable de unos soportes físicos de carácter material y naturaleza inmueble, a través de los cuales pueda evidenciarse la verosimilitud histórica, el significado, y el recorrido del itinerario". rritorios, sino que es el origen per se de su(s) configuración(es), en tanto establece inevitables relaciones de intercambio y ocupación en el espacio geográfico, su valoración precisa del reconocimiento y revisión de la huella e impacto que lo hace vinculante con él.

Retomando la Carta de ltinerarios Culturales -elaborada por el Comité Científico Internacional de Itinerarios Culturales (CIIC) (lcomos. 2008)-, en la definición que hace de los itinerarios culturales, se ratifica su premisa humanizante al definirlos como:

a. Ser resultado y reflejo de movimientos interactivos de personas, intercambios multidimensionales, contiguos y recíprocos de bienes, ideas, conocimientos y valores entre pueblos, países, regiones o continentes, a lo largo de considerables periodos de tiempo.

b. Haber generado una fecundación múltiple y recíproca, en el espacio y en el tiempo, de las culturas afectadas que se manifiesta tanto en su patrimonio tangible como intangible.

c. Haber integrado en un sistema dinámico las relaciones históricas y los bienes culturales asociados a su existencia [...] (lcomos, 2008).

Esta definición ratifica la idea del itinerario como una construcción territorial, es decir, como adaptación de las necesidades del hombre al entorno físico y natural, y que se ha ido llenando, no solo de soportes físicos, sino de prácticas culturales y de contenidos simbólicos y significativos, es decir, de referentes intangibles de la memoria ferroviaria. En los elementos definitorios que configuran el itinerario cultural incluidos en la carta, se hace referencia directa a esta acepción territorial y la explica así: el entorno territorial, ya sea natural o cultural (urbano o rural), enmarca al itinerario cultural, le proporciona un particular ambiente, caracterizado por elementos y valores tanto de naturaleza física como inmaterial, y es fundamental para la comprensión, conservación y disfrute del mismo.

Es la posibilidad de analizar el territorio, por efectos metodológicos, en sus dos acepciones, la natural y la cultural, que son entidades indivisibles, pero que se pueden comprender mejor en la semántica del imaginario social del territorio.

El enfoque metodológico debe alinearse, por tanto, con las problemáticas planteadas, que permitan identificar los elementos de valoración integral del itinerario, esto es, en su doble connotación de flujos y dinámicas de intercambio cultural y espacial de apropiaciones, por una parte, y significaciones referidas al espacio habitado, por otra. Por su condición patrimonial y categoría de itinerario cultural, además del potencial como recurso cultural para el desarrollo a escala humana, será necesario construir discursos patrimoniales enriquecidos en el diálogo abierto entre las evidencias tangibles e intangibles a través de la historia en sus diversas expresiones ${ }^{1}$ y los imaginarios sociales.

De las apropiaciones y significaciones: el itinerario como creación y representación

Santos (1996) explica la noción formal del espacio como "un híbrido" conformado por un "sistema de objetos y un sistema de acciones", y en alusión a ello, el espacio del itinerario cultural en su intima relación con el territorio y las dinámicas de intercambio multidimensionales, de allí la necesidad de aportar en la construcción de los discursos patrimoniales, alternativas de descripción, análisis e interpretación de los valores de conjunto compartidos entre los diferentes actores sociales, a partir de las construcciones mentales sobre el "[...] espacio percibido, sentido y vivido" (Comerci, 2004).

Si bien, para su identificación y análisis se precisa del conocimiento de sus partes y entornos particulares, para su interpretación y valoración como conjunto, se prescinde de fraccionamientos, y se construye en el esfuerzo por reconocer las relaciones compartidas e intersubjetivas que se manifiestan en los escenarios de convivencia del itinerario, a fin de determinar las claves de identidad que han consolidado lugares comunes de memoria e imaginarios.

La relación de interdependencia que se establece entre las evidencias materiales y el patrimonio intangible del itinerario cultural, se soporta en las conclusiones del Congreso Internacional del CIIC de lcomos celebrado en Pamplona (España) en $2001^{2}$, y por tanto contribuyen a definir los criterios para su identificación y catalogación. De allí la importancia de contrastar sus evidencias, no solo en las dinámicas históricas de consolidación, sino en los procesos de legitimación social (apropiación), lo que se constituye en garantía de permanencia y perdurabilidad. Así, las significaciones y valoraciones que se hagan del itinerario podrán 
ofrecer distintos matices y reinterpretaciones de funcionalidad sobre el mismo soporte histórico, material y geográfico, pero nunca perderán su presencia simbólica y significativa.

Sin duda, en las últimas décadas estamos asistiendo a un cambio cualitativo en la concepción estática del patrimonio cultural que nos confronta con la interpretación que se hace del patrimonio como creación, negando su existencia inmutable, que si bien se fija en la memoria y las versiones oficiales de identidad, plantea nuevas posibilidades de reconocimiento, que, como lo refiere Smith (2001, p. 42) "[...] el patrimonio es un proceso cultural que tiene que ver con la negociación de la memoria, la identidad y el sentido de lugar”. Y agrega: "Es un proceso activo de recordar, olvidar y conmemorar que se implementa para ayudar a navegar y mediar el cambio cultural y social, así como temas sociales y políticos contemporáneos”.

Se incorpora entonces la necesidad de generar procesos de activación de la memoria, no solo como estrategia de gestión para la conservación del patrimonio, sino como un diálogo cultural abierto y renovado entre todos los actores sociales.

Las apropiaciones como procesos de legitimación social del patrimonio cultural, y las significaciones $^{3}$ como sus formas de representación y creación simbólica, sellan la brecha entre el discurso estático y oficial del patrimonio y las versiones locales del imaginario social, que, como creación y proceso cultural, son sujetos de constante renovación, y amplían el espectro y la dimensión del objeto patrimonial al escenario de la legibilidad social.

A propósito de la necesidad de trascender lo que Smith (2001) llama el "discurso oficial del patrimonio”, o Choay (2007), en relación con el patrimonio edificado, "la museificación del patrimonio como ilusión narcisista”, por una versión antropogénica y de convivencia con la memoria:

[...] Este papel propedéutico del patrimonio edificado concerniría idénticamente a todos los miembros de sociedades protésicas. Como su objetivo no sería ya la conservación de un patrimonio que tiene, en tanto que tal, un interés solamente relativo y limitado, sino la conservación de nuestra capacidad de continuarlo y de reemplazarlo, esta propedéutica exigiría repensar y reinstaurar de arriba abajo la totalidad de nuestras actuales prácticas patrimoniales (Choay, 2007, p. 235).

En este repensar las prácticas patrimoniales, la historia deja de ser un asunto exclusivo del pasado, de nostalgia y evocación de los hechos representativos, y pasa a ser un asunto vivo de legitimación social que se construye en los relatos que tienen pervivencia y significación. Así es posible encontrarnos a veces con una mezcla de vivencias a la manera de mitos y realidades que están amparados por una versión humanizada del patrimonio como un asunto existencial y no propiamente como un préstamo del pasado. En esta perspectiva, la propuesta de plantear el itinerario cultural en un escenario de creaciones y representaciones resulta acorde con su propia escala y dinámica de intercambio y fecundación, esta vez de apropiaciones como aprendizajes, y de significaciones como creaciones y procesos culturales.

\section{Los discursos emergentes: un asunto} del imaginario y legitimación social

Este análisis ha permitido poner en diálogo los mitos y realidades entre las evidencias documentales y las huellas físicas, como vestigios antrópicos de ocupación y transformación del espacio y territorio. Como prueba de ello, los procesos de voladura con dinamita en la construcción del Túnel de la Quiebra son evidenciados por la arqueología industrial con las cicatrices que aún son legibles en la roca, y también con las pruebas documentales tomadas del periódico del ferrocarril y de los datos de cuentas y compras para su construcción ${ }^{4}$. Una versión que entra en diálogo con las historias de vida y el mito, que anclados en la memoria e imaginario comunitarios, magnifican el reto y la valentía de los obreros en la construcción de tan titánica obra de la ingeniería, con la versión de haber sido construido, como coloquial y cotidianamente se dice, "a pico y pala”.

En esta perspectiva se cruzan muchos relatos que se constituyen en creaciones y representaciones de la memoria e identidad ferroviaria, que resaltan, no solo su valor histórico, tecnológico y de impacto social, sino su estrecha relación con el territorio, como espacio de interacción y de apropiación.
3 “[...] Creyendo como Max Weber que el hombre es un animal inserto en tramas de significación que el mismo ha tejido, considero que la cultura es la urdimbre y que el análisis de la cultura ha de ser por lo tanto, no una ciencia experimental en busca de leyes, sino una ciencia interpretativa en busca de significaciones. Lo que busco es la explicación, interpretando expresiones sociales que son enigmáticas en su superficie" (Geertz, 1987, p. 20).

4 En la apertura del túnel se removieron 96.212 metros cúbicos de roca; por razón del exceso de excavación para el revestimiento, se removieron 14.320 metros cúbicos; lo que hace un total de 110.532 metros cúbicos. En este trayecto se invirtieron 540.000 libras de dinamita, o sea 144 libras por cada metro lineal de Túnel, o 5,4 libras por metro cúbico de material removido (Tisnés y Zapata, 1980, p. 323). 
De otra parte, el ferrocarril, y especialmente la máquina, adquieren una fuerte connotación en el relato tanto en lo historiográfico como en el imaginario comunitario. La máquina se constituye en el elemento más emblemático de la memoria ferroviaria y por tanto del itinerario, de un lado, por su connotación y valor simbólico que, en una sociedad de profunda filiación conservadora de convicciones católica y ortodoxa de la época, llegó a suscitar múltiples interpretaciones cercanas incluso a lo pecaminoso, teniendo en cuenta que tras su presencia venía el cambio y una sociedad más liberal y emancipadora; de otro lado, la máquina sintetiza el advenimiento y el desarrollo de la era tecnológica e industrial, y toda su connotación de modernidad. Para muestra basta con citar algunas alusiones de la época sobre el desarrollo industrial en publicaciones monográficas y guías publicitarias de ciudad:

Medellín es el centro de un activo comercio de importación y de exportación. Las industrias alcanzan notable desarrollo. Hay y Peyrat, 1916).
Figura 2: Superior izq: Representaciones del imaginario ferroviario en los talleres de participación retrospectiva. Foto del autor Superior der.: Vaporina No. 45 al frente de la Estación Cisneros. Foto del autor. Inferior izq. y der. Escudo municipal y logosímbolo de los 100 años de su fundación, 2012 tomado de la página web del municipio de Cisneros

Fuentes:

Archivo fotográfico Germán Jaramillo y página web del municipio de Cisneros
De algunos años a esta parte se viene perfilando la fisonomía industrial de la ciudad de Medellín. Y ya ha perdido el tipo artesanal de la producción, convirtiéndose, cada vez con mayor intensidad, en un poderoso núcleo de grandes industrias nacionales. Sólo en lo que respecta a la industria textil, por ejemplo, el capital fijo invertido en ella monta a $\$ 14.744 .382 .00$, mientras el número de obreros y empleados que ocupa, según investigación directa, alcanza a 5.938 [...] (Cervecería Unión, 1941).

En el trabajo participativo y diálogo de saberes con las comunidades, se identificaron cinco centralidades del trayecto intermedio de la ruta Medellín-Puerto Berrío (Botero, Porce, Santiago, Limón y Cisneros), en la transición del llamado paso de la Quiebra que conecta las divisiones de los cañones del Porce y Nus, y que por su configuración de asentamientos exnovo, significación y nivel de conservación, permitieron una lectura integral y especialmente representativa del itinerario.

Del primer instrumento que se aplica a los talleres de participación en el diálogo de saberes con las comunidades, y que se fundamenta en las cartografías de la memoria como retrospectiva, se recogen algunos testimonios a manera de creaciones y representaciones, que han sido clasificados en las categorías conceptuales:

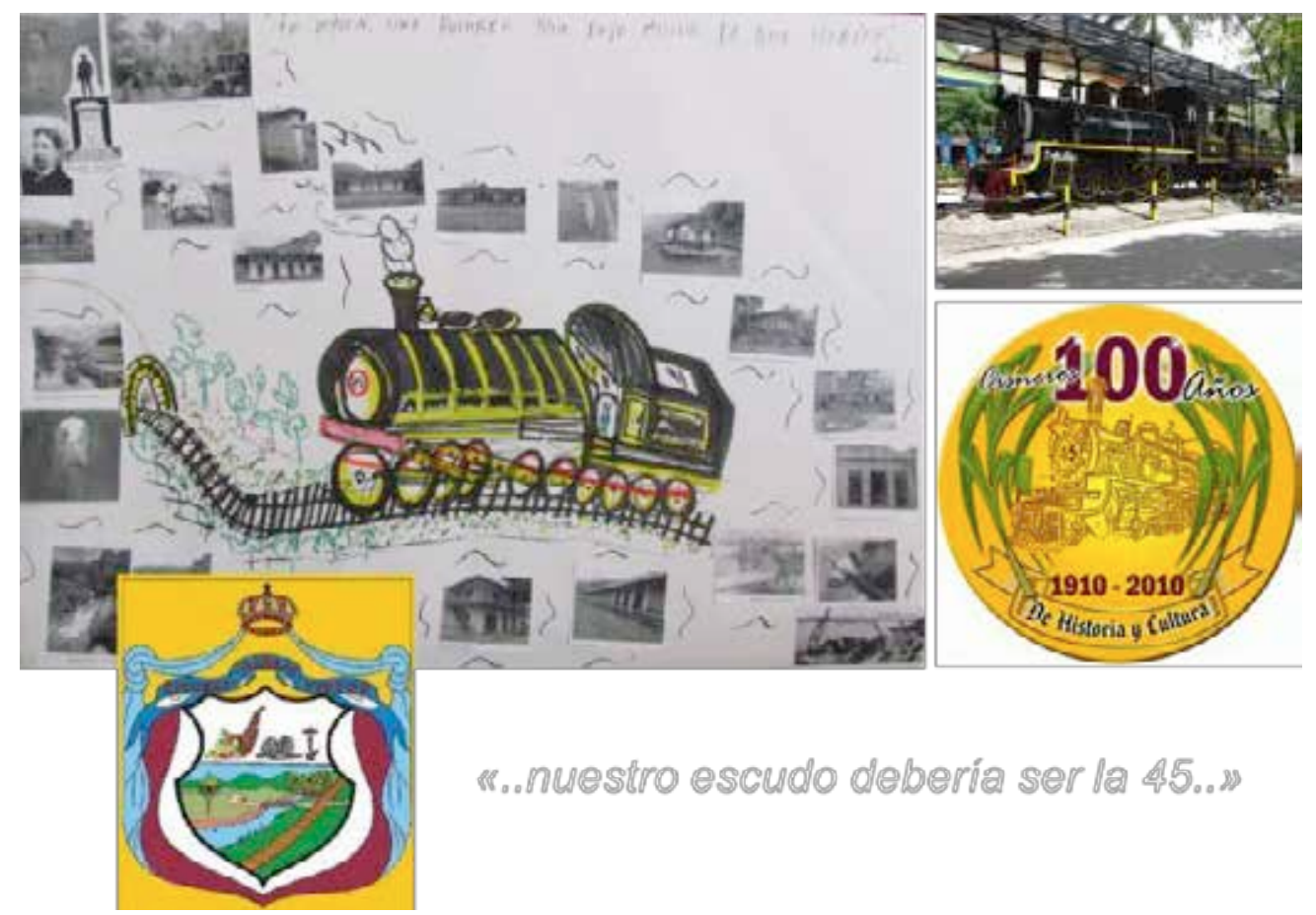


identidad, valores de conjunto compartidos, imaginarios colectivos, niveles de apropiación y capacidad de protección, que dan cuenta de la representatividad de la ruta como categoría patrimonial de itinerario cultural.

Como reafirmación de identidad se señala la importancia de la máquina como símbolo en la comunidad cisnereña, en un acto mayoritario de complicidad, que validan la imagen de la máquina de vapor No. 15, como escudo alternativo del municipio, aún por encima del escudo oficial, donde prevalece la imagen del Nus y el cuerno de la abundancia, en alusión a la fertilidad y riqueza agrícola del territorio que ocupa. De allí que sea común escuchar expresiones alusivas como: "Nuestro escudo del municipio debería ser la 45 ".

Como valores de conjunto compartidos surgen nuevas versiones que se asocian a la integralidad del itinerario con el territorio y los procesos antrópicos de explotación e interdependencia, que demuestran lo abarcante de la cultura ferroviaria en un proceso simbiótico de representación entre los ámbitos naturales productivos y de equipamiento ferroviario, que se cargan de significación. El agua, como fuente común en los procesos de producción agrarios (para el caso piloto de los cultivos de caña y la producción panelera), de generación de energía y fuente de vida, de abasto al aprovisionamiento a las calderas de las vaporinas durante más de 80 años de frecuencia en la vía férrea, se constituye en un aliado común del imaginario ferroviario, que se carga de valor simbólico, en alusión a la región que atraviesa. El Valle del Nus, cuyo nombre deriva del vocablo Tahamí "Nusika", que significa "princesa del valle de muchas aguas" es la prueba, en las voces de sus habitantes, de estas nuevas versiones de identidad e integralidad con el territorio.
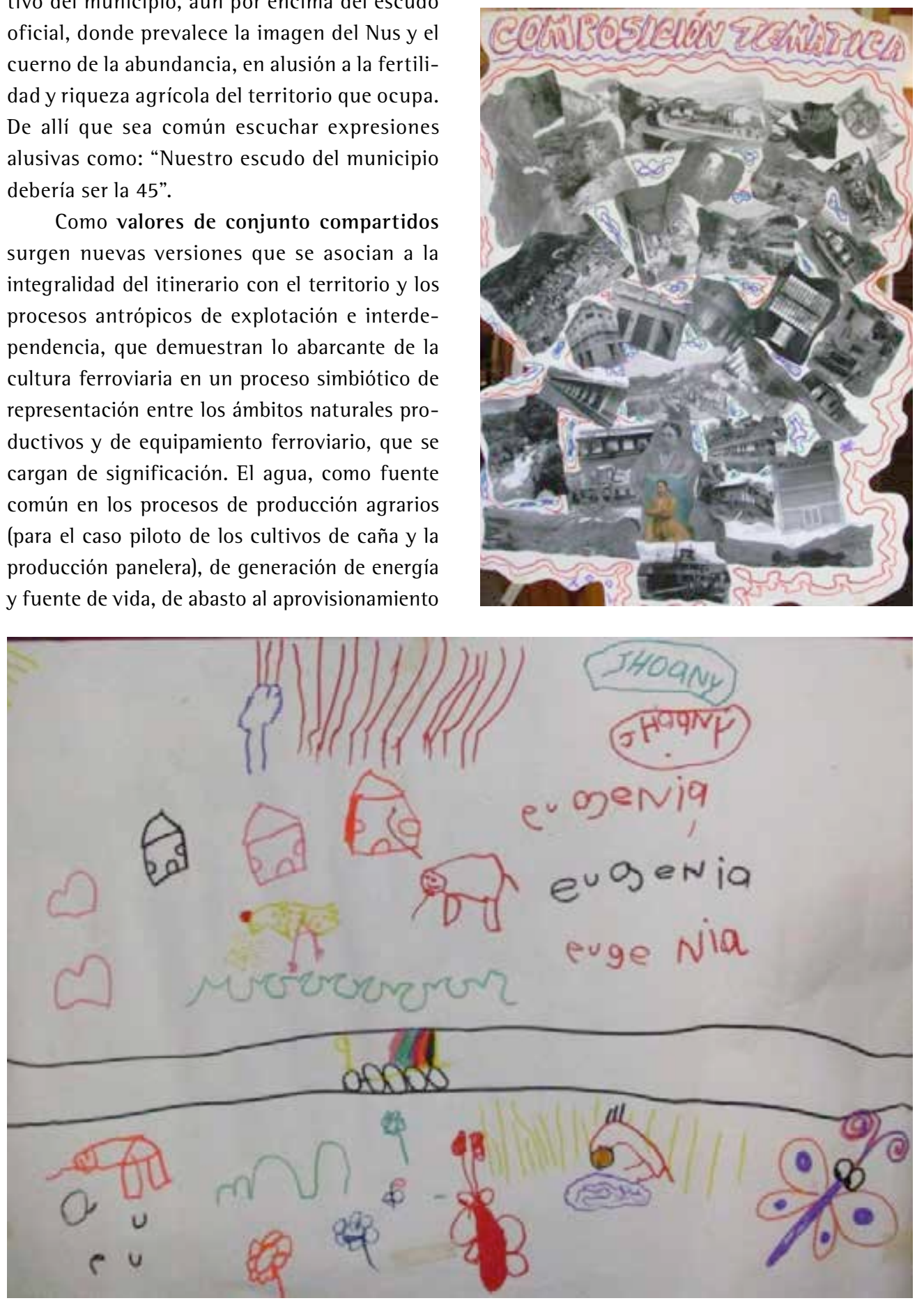

Figura 3:

Composición temática elaborada en los talleres comunitarios que representa la integralidad del ferrocarril con el territorio Fotografía: Autor

Figura 4:

Dibujo de un niño que plasma su imagen del municipio de Cisneros en el taller participativo de creación y re-creación Fotografía: Autor 
5 Testimonio del señor Dorancé Bedoya pensio nado del ferrocarril de Antioquia, en el taller participativo con la comunidad de Botero: "Creemos y recreemos nuestra memoria", realizado el 11 de noviembre de 2011.

6 Testimonio de doña Aurora Carmona, líder de la Asociación de Mujeres del cañón del Porce de corregimiento y estación de Porcesito. Taller: "Creemos y recreemos nuestra memoria", realizado el 11 de noviembre de 2011.

7 Testimonio de Aurora Carmona en el mismo taller.

8 Entrevista realizada al señor Mario Alveiro Carmona, operario de moto-rodillo en noviembre de 2011.

Figura 5:

Fiesta de la Virgen del Carmen, procesión entre las estaciones de Santiago y Cisneros Fuente: Archivo personal de Fredy García
Para Don Dorancé, jubilado del ferrocarril y habitante del corregimiento de Botero, la vía férrea "son dos brazos abiertos e infinitos que nos conectan", no obstante la multiplicidad de paisajes, regiones y geografías que atraviesa ${ }^{5}$.

En el imaginario colectivo, el sonido del "pito" de las locomotora, aparte de anunciar el paso por la comarca, venía cargado de significaciones que invocaban sentimientos de alegría por la llegada, de tristeza por las despedidas, de canto a la memoria de los fallecidos, entre otros. Las mismas voces de ferroviarios, esposas e hijos al escuchar las grabaciones sonoras como invocación a la memoria lo manifiestan: "Las esposas y los hijos sabíamos, por el pito, cuál era la locomotora donde venían nuestros padres" ${ }^{\text {.Y }}$ en alusión a momentos solidarios de luto por el fallecimiento de seres queridos: "También existía el pito funerario que era más largo y triste"7.

Las comunidades de las diferentes estaciones y corregimientos asociados al corredor férreo, aún los grupos sociales que habitan distantes a ellas, y que por alguna razón tuvieron la oportunidad de frecuentar el ferrocarril, manifiestan altos niveles de apropiación en la evocación a su memoria, que no pueden ocultarse y que, de paso, se preguntan con regularidad: “¿Por qué se acabó en ferrocarril?” No se escapan las nuevas generaciones, que aún y a pesar desconocer la operación de este medio de transporte sobre el territorio, que pueda emerger e incorpore en sus imaginarios y representaciones mentales.

Al revisar los sentidos de pertenencia y apropiación social, debe existir una coexistencia y simultaneidad con la capacidad de protección para que pueda validarse, y en esa medida se constituye en un anticipo a la medición de las voluntades y capacidad de autogestión que nacen de los actores. Así, en las nuevas dinámicas de apropiación de los sistemas de movilidad artesanal del ferrocarril, como alternativa de emergencia y sobrevivencia de estas comunidades apartadas, descontextualizadas de todo sistema estructurante del territorio, y en particular, ausentes de estado, surgen sentimientos de cuidado y conservación que hacen del patrimonio ferroviario una memoria que se resiste a morir. Así, de las voces de los operarios de estos sistemas de movilidad se reconocen expresiones como: "Nosotros fuimos los que abrimos el paso a los moto-rodillos. Limpiamos permanentemente la vía de maleza, despejamos derrumbes y hacemos mantenimiento constante" ${ }^{8}$. $Y$ como alusión a la versatilidad en respuesta a las necesidades de movilidad de las comunidades: "La ruta de la Victoria se hace periódicamente para recoger gente de las veredas que salen a los caminos reales [...] también sirve de ruta ambulancia para

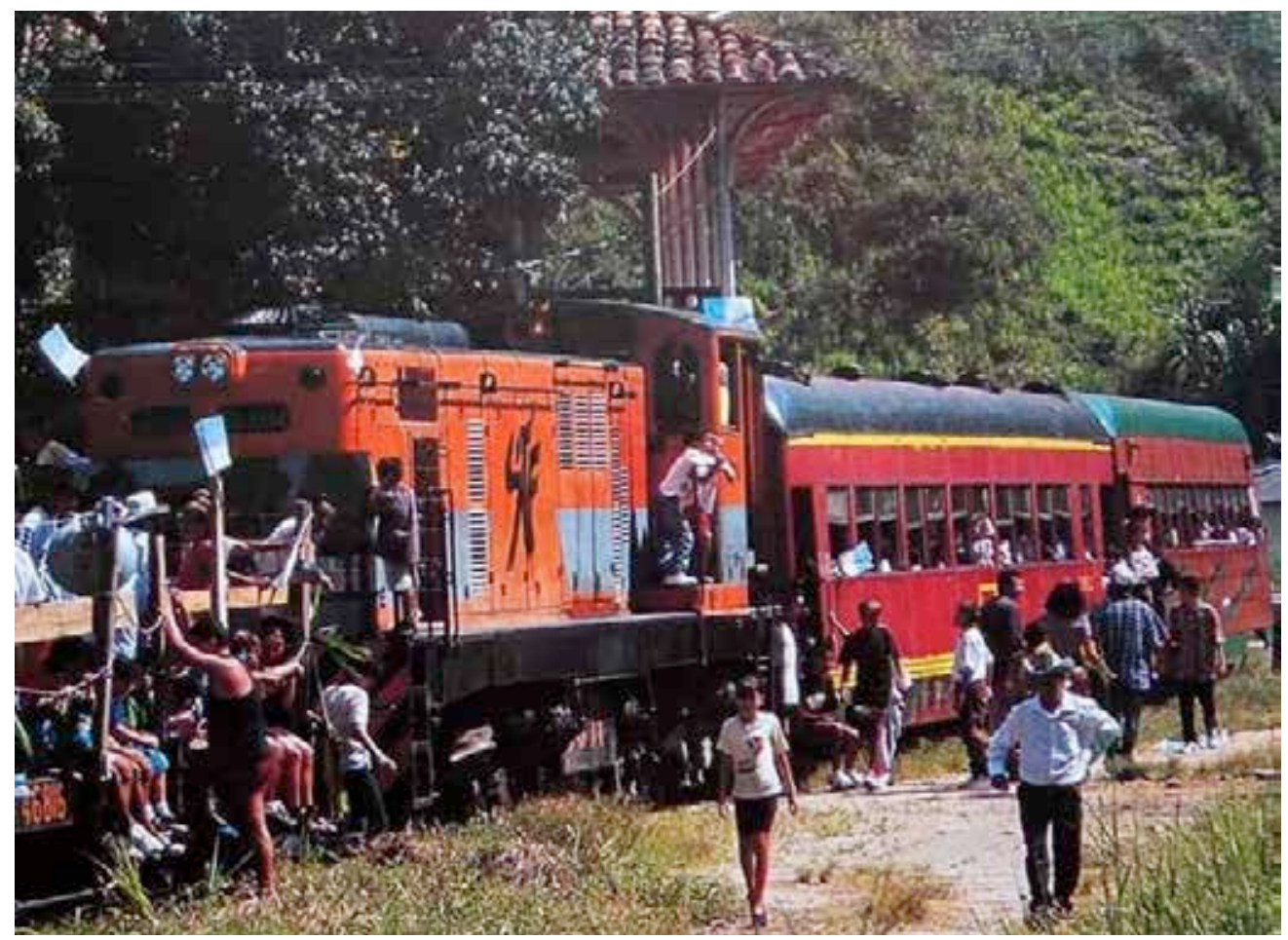


atender casos de enfermos o emergencias [...] se pide al celular" 9 .

En otro escenario de participación, en particular con las madres cabeza de hogar que han ocupado la estación Porce desde el cierre de operación del ferrocarril, y lo han convertido en espacio compartido de vivienda, de reunión de la "Asociación de Madres del Cañón del Porce" y emisora comunitaria, se ha podido confirmar, por el estado de conservación integral del inmueble, un sentimiento compartido de protección, no obstante su condición provisional de ocupación y el reconocimiento de que en un futuro será necesario devolverlo a su funcionalidad inicial. De sus voces es recurrente la expresión: "nosotras no invadimos la estación, la tomamos prestada”.

En la estación Botero, hoy ocupada por familias desplazadas, la misma comunidad valida su condición informal de ocupación a través de la metáfora: "gracias al calor humano es que las paredes se mantienen en pie" ${ }^{10}$.

En lo que toca a lo religioso, la tradición y culto católico de las comunidades asociadas al itinerario han incorporado en sus fiestas la devoción por la Virgen del Carmen como advocación de la Virgen María, adoptada como patrona de los ferroviarios y en general, por extensión, de los transportadores en Colombia. A lo largo de la vía, las comunidades han dispuesto pequeñas imágenes y grutas como tributo a la virgen, y cada año, a mediados del mes de julio, es expuesta y llevada por los rieles en la tradicional "Fiesta de la Virgen", invitando a las comunidades a su veneración.

Desde el punto de vista del carácter evocador, simbólico y conmemorativo. y en consideración al valor que se atribuye al ferrocarril como patrimonio industrial, se evidencian elementos singulares asociados a la identidad de los lugares, la historia y gesta de su construcción y sus protagonistas. Tal vez, el que más ha trascendido la historia oficial y se ha anclado a la memoria e imaginario de las comunidades, ha sido el connotado ingeniero Alejandro López, quien dejó como consigna que a su muerte sus restos fueran ente-
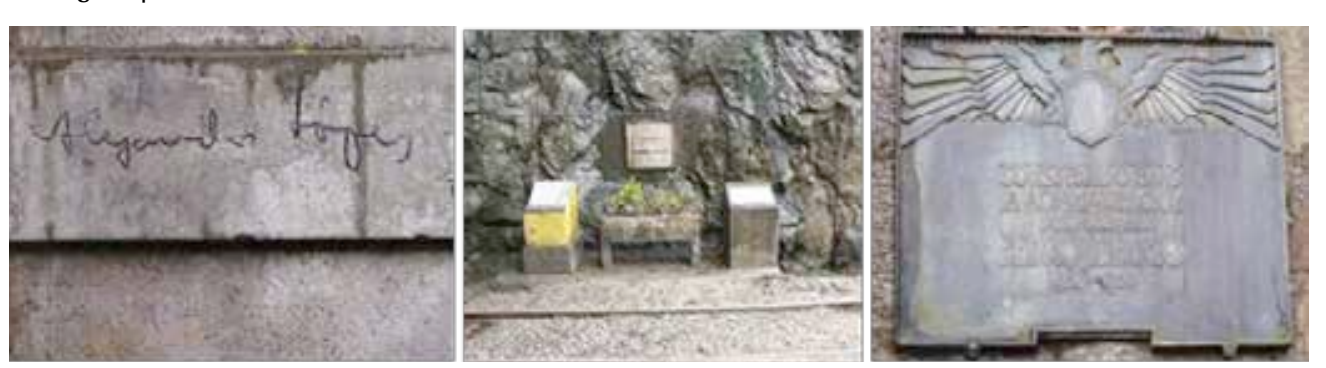

rrados en la puerta del túnel de La Quiebra, obra de ingeniería que se construyó con su proyecto de tesis de pregrado de la Facultad de Minas y que se ha constituido en una de las obras de ingeniería más emblemáticas del ferrocarril de Antioquia y la nación, por lo que significó como reto al desarrollo de la ingeniería y avance tecnológico del transporte y comunicaciones; también por las nuevas relaciones de intercambio multidimensional que se facilitaron con la apertura comercial y cultural de la provincia de Antioquia al mundo y todo lo que representó en el cambio de ideario.

Entre las manifestaciones de la cultura inmaterial vinculantes con el itinerario toman asiento expresiones musicales coloquialmente acuñadas con el término de música de carrilera, con una amplio repertorio de tonadas populares de influencia norteña (corridos mexicanos) y del sur del continente (tangos, zambas), que dan cuenta de los encuentros y desencuentros, y en general, temas alegóricos a las vivencias propias de la cotidianidad en los poblados ferroviarios, posadas, restaurantes, cantinas y recorridos en tren.

\section{Conclusiones}

Desde el punto de vista práctico, la implementación de las técnicas e instrumentos aplicados en las cartografías de la memoria y construcción de sueños, ha permitido develar la hibridación entre objetos y acciones (Santos, 2000), en una dialéctica donde los espacios adquieren significado. Esta relación, trasladada al itinerario cultural, se expresa en la dinámica que se establece entre los flujos y permanencias. Así, lo que se ha dado en llamar las “apropiaciones y significaciones”, está en íntima relación con las construcciones mentales sobre el espacio percibido, sentido y vivido, y por tanto ameritan ser contrastadas en los contenidos tangibles del itinerario cultural. La lectura de apropiaciones y significaciones fundamentada en la metodología del taller se ha concretado en la creación de escenarios de
9 Testimonio del señor Mario Alveiro Carmona en la misma entrevista.

10 Testimonio de la señora Claudia Valdés, habitante en la estación Botero. Taller "Creemos y recreemos nuestra memoria", noviembre de 2011.

Figura 6:

(lzq.) tumba del ingeniero Alejandro López, de cuya tesis de grado derivó la decisión técnica de construcción del túnel de La Quiebra. (Centro) conjunto de placas conmemorativas y tumba del ingeniero A. López. (Der.) Placa alusiva al gobernador de Antioquia en cuya administración se construyó el túnel de La Quiebra Fotografías: Autor 
diálogo de saberes y procesos de participación, en la búsqueda de una construcción colectiva de la memoria ferroviaria, centrada en las tres dimensiones temporales del ferrocarril de Antioquia: pasado, presente y futuro. A partir de las experiencias que hacen parte de la vida cotidiana de los ciudadanos, de la historia no oficial de la que solo ellos pueden dar cuenta y sin la cual sería imposible pensar el ferrocarril en clave de itinerario cultural, integrador del territorio, la comunidad y la cultura.

Las sociedades multiculturales y globalizadas se enfrentan hoy día a un nuevo reto de la gestión que deberá superar las contradicciones entre los modelos neoliberales de estandarización de la cultura, entrecruzados con preocupaciones emergentes de escala regional, localista e identitaria que promueven el reconocimiento de las tradiciones, lo que obliga a encontrar fórmulas consensuadas y negociadas. Es allí donde aplican estrategias como el diálogo abierto de saberes y la confluencia armónica entre el discurso oficial y las versiones locales.

Uno de los objetivos de la Carta de ltinerarios Culturales incorpora la perspectiva de la gestión cuando establece la necesidad de "plantear los mecanismos fundamentales para desarrollar el conocimiento, la valoración, la protección, la conservación y la gestión de los Itinerarios Culturales" (lcomos, 2008), donde la gestión, más allá de ser una fase del proceso, debe convertirse en un agente catalizador y dinamizador. Como ciencia práctica debe apuntalarse en el método científico, lo que se corrobora fielmente en su naturaleza sistémica y holística. Debe asumirse como un proceso transversal y transdisciplinar que, por su condición dinámica e interpretativa, es sujeto de renovaciones, transformaciones, apropiaciones y significaciones, como lo ha podido demostrar esta experiencia en las acciones y procesos de participación, propios de coyunturas políticas, económicas y socio-culturales de cada momento histórico.

La gestión como proceso de activación del itinerario es el todo y no una fracción del proceso. Cuando se investiga, se valora y se interviene, sea cual fuese el orden en la fase del proceso, se está haciendo gestión del itinerario en la activación de los valores compartidos, y especialmente en los procesos sociales de construcción y consolidación de la memoria e identidad como estrategia para el desarrollo.
Si bien la comunidad científica y el Comité Científico Internacional de ltinerarios Culturales no han desarrollado una reflexión teórica y epistemológica en torno a la gestión patrimonial de los itinerarios culturales, en cambio sí han logrado identificar los elementos definitorios y prácticos, que de paso guardan una relación muy estrecha con los principios antes mencionados del patrimonio como base para el desarrollo.

En las dinámicas generadas de lnvestigación-Acción-Participativa, IAP, se vislumbra un cambio de paradigma de lo expuesto por Choay: "la museificación del patrimonio como ilusión narcisista”, por una versión antropogénica y de convivencia con la memoria, que se activa en el diálogo de saberes y se proyecta como una alternativa del patrimonio en constante renovación y actualización, sin que se pierdan los valores esenciales que dan identidad al itinerario, antes por el contrario, salgan enriquecidos y fortalecidos.

Como proceso científico y en prospectiva se señala la importancia de la investigación como un cúmulo de acciones encaminadas a generar un espacio de reafirmación de identidades, acuerdos en medio de los desacuerdos y toma de decisiones en el escenario político y de acción, como aproximación a un modelo de gestión patrimonial.

Existe una deuda pendiente por parte de las instituciones que velan por la tutela del patrimonio de revisar estas rutas en íntima relación con otras que se han desarticulado por antecedentes similares, y en escalas más abarcantes del territorio, que aportaría, de paso, una posibilidad de riqueza en el flujo e integración de saberes y prácticas multiculturales y pluriétnicas, como el mayor activo de nuestra verdadera nacionalidad. Por ello la gestión debe entenderse como un proceso dialéctico y gradual abierto a la concertación y construcción colectiva de identidades en su multiplicidad de escalas, y que de manera propedéutica del territorio permita hilvanar los discursos, creaciones y prácticas culturales en un escenario común de lecciones y aprendizajes significativos. El ordenamiento territorial y las decisiones sobre el manejo del itinerario cultural, ameritan un tratamiento especial y diferenciado con capacidad de convocatoria en el escenario regional y suprarregional.

Como consideración final, el capital del itinerario está representado en sus comunidades no solo como sujetos portadores de memoria sino como agentes de cambio y activación, por ello el 
énfasis del modelo de gestión participacionista. Su ámbito y escala de actuación debe construirse en el escenario de la cotidianidad, en la escala local, y enriquecerse gradualmente en la medida en que se activan la memoria y los imaginarios de las comunidades participantes. Podría decirse que la construcción del modelo es un ejercicio permanente e inacabado que se extiende al territorio como escenario comunitario; algo similar a lo que fue el proceso de construcción del ferrocarril, al punto de convertirse en la síntesis de una ruta integrada de intercambio multidimensional que impactó en múltiples paisajes culturales.

\section{Referencias}

Cervecería Unión (1941). Monografías de Antioquia. Medellín: Cervecería Unión. Recuperado en https://goo.gl/WqS6fa.

Choay, F. (2007). Alegoría del patrimonio. Barcelona: Gustavo Gili.

Comerci, M. E. (2004). Formas, representaciones, actores sociales y procesos en Chos Malal. Huellas, 9(139), 135-162.

Geertz, C. (1987). La interpretación de las culturas. Barcelona: Gedisa. Recuperado en http://goo. gl/oukrQQ.
Icomos (2008). Carta de itinerarios culturales. Quebec: lcomos. Recuperado en http://www. international.icomos.org/charters/culturalroutes_sp.pdf

Lenis, C. A., Jaramillo, R. L. y Vélez, A. (2010). Cartografías para un bicentenario. Medellín: Alcaldía de Medellín.

Olano, R. y Peyrat, J. (1916). Guía de Medellín y sus alrededores. Medellín: Sociedad de Mejoras Públicas; New York: R. Echavarría y Co. Recuperado en https://goo.gl/ZG5pCW.

Ortega, J. (1998). El patrimonio territorial: el territorio como recurso cultural y económico. Ciudades, 4, 33-48.

Santos, M. (1996). Metamorfosis del espacio habitado. Barcelona: Oikos-Tau.

Santos, M. (2000). La naturaleza del espacio. Técnica y tiempo. Razón y emoción. Barcelona: Ariel. Recuperado en http://goo.gl/FOSyNl.

Smith, L. (2011). El “espejo patrimonial”. ¿llusión narcisista o reflexiones múltiples? Antípoda, (12), 39-63. Recuperado en https://goo.gl/ mJjYrT

Tisnés, R. M. y Zapata, H. (1980). El ferrocarril de Antioquia: historia de una empresa heroica. Medellín: Empresas Departamentales de Antioquia. 